\title{
Crustacean biodiversity through the marine fossil record
}

\author{
J. John Sepkoski, Jr. (†) \\ Department of the Geophysical Sciences, University of Chicago, Chicago, IL 60637, USA
}

Keywords: Crustacean biodiversity, marine fossil record, extinction rates, Ostracoda, Malacostraca, Cirripedía

\begin{abstract}
Approxímately 2,600 genera of marine crustaceans have been recognized in the fossil record, and crustaceans constitute the major component of marine arthropod diversity from the midPaleozoic to the Recent. Despite problems of sporadic fossil preservation and/or taxonomic ambiguity, some general statements can be made about the history of crustacean biodiversity, based on global taxonomic data bases. Ostracodes were the first major group to radiate, attaining high diversity during the Ordovician Period with other members of the Paleozoic evolutionary fauna; rates of extinction and responses to mass extinctions were also similar to those of groups within the Paleozoic fauna. Malacostracans and barnacles (cirripedes), the two other crustacean groups with important fossil records, had minor diversity throughout the Paleozoic Era. Both groups experienced diversification from the mid-Mesozoic to Recent with lower extinction rates, as characteristic members of the Modern evolutionary fauna.
\end{abstract}

\section{Contents}

$\begin{array}{ll}\text { Introduction } & 213 \\ \text { Caveats } & 214 \\ \text { Biostratigraphy } & 214 \\ \text { Ostracode taxonomy } & 214 \\ \text { Malacostracan preservation } & 214 \\ \text { Crustacean diversity in the fossil record } & 214 \\ \text { Relative to other arthropods } & 214 \\ \text { Diversity of major groups in the fossil record } & 215 \\ \quad \text { Ostracodes } & 216 \\ \text { Barnacles } & 217 \\ \quad \text { Malacostracans } & 217 \\ \text { Comparison to Phanerozoic diversification } & 219 \\ \text { Summary } & 220 \\ \text { Acknowledgements } & 220 \\ \text { References } & 220 \\ \text { Addendum } & 221\end{array}$

\section{Introduction}

Arthropods constitute an important component of the fossil record, just as they constitute a major part of the living fauna both on land and in the oceans. In the marine realm, approximately 16 percent of all described genera of fossil animals are arthropods; on land, fossil arthropods at the family level have proportions that are even higher (Labandeira and Sepkoski, 1993). Among fossil marine arthropods, a major constituent is the Crustacea, including predominantly ostracodes, cirripedes, and malacostracans. Together with minor groups, they include 45 percent of described arthropod fossil genera from marine strata, exceeded only by the diverse and rapidly evolving trilobites of the $\mathrm{Pa}$ leozoic Era.

In this contribution, I examine these numbers for crustaceans as they relate to geologic time and therefore to evolutionary history and fossil preservation. Diversity, or taxonomic richness, of fossils in taxonomic databases provides a variety of quantitative information. The simplest is just our knowledge of the fossil record: The number of fossil taxa described can be compared to other measures of importance, such as modern diversity or fossil abundance, to deduce the quality of our knowledge of the fossil record. For example, copepods are the most abundant arthropods in modern marine pelagic ecosystems, but their fossil record is minimal. But even with varying quality of the fossil record, qualitative statements can be made about evolutionary history, which is the usual goal of studies of fossil diversity.

The data analyzed here are based upon a compilation of geologic ranges of all marine animal genera that I have described previously (e.g., Sepkoski, 1996, 1997). The compilation has in- 
volved summarizing standard sources, such as the Treatise on Invertebrate Paleontology, and reviewing primary literature to increase stratigraphic resolution of first and last appearances and to add newly described fossil genera. The taxonomic level of the genus is employed as a compromise between the immense, idiosyncratic, and historically complicated taxonomic descriptions of fossil species and the limited numbers of crustacean families described from the fossil record (therefore subject to small-sample variation). At the taxonomic levels of both genus and family, some might object that supra-specific taxa are arbitrary constructs and may not reflect any evolutionary patterns. However, empirical (Sepkoskì et al., 1981) and model (Sepkoski and Kendrick, 1993) studies have indicated that traditional genera and families reflect species-level patterns of diversity quite well (see also Gaston and Williams, 1993). In fact, when the potential preservation of animals is quite low, as in the case of many crustaceans, higher taxa may better reflect patterns of underlying species diversity than fossil speices themselves (Sepkoski and Kendrick, 1993).

Below, I present a few more caveats about the data. I then illustrate summaries of the history of genus diversity for the major fossil classes of marine crustaceans and compare these to the history of the three great evolutionary faunas of the Phanerozoic.

\section{Caveats}

In attempting to interpret crustacean div\&rsity through geologic time, it is clear that both the quantity of taxonomic attention and the quality of preservation influence patterns seen in taxonomic databases. Neither attention nor quality is ideal for crustaceans, but even in an imperfect world major evolutionary trends in diversity are potentially perceptible. Below, I discuss three problems and their resolutions:

\section{Biostratigraphy}

Crustaceans have not been used as index fossils through most of the Phanerozoic geologic record. Ostracodes are an exception and have been used occasionally as zonal fossils through parts of the Mesozoic and Cenozoic. However, crustaceans as a whole have been viewed as having a sporadic fossil record and therefore of limited use in telling time. Thus, there has been limited impetus for detailed search and study.

\section{Ostracode taxonomy}

The volume on ostracodes in the Treatise on Invertebrate Paleontology (Benson, 1961) was a major breakthrough for the understanding of the systematics of these fossils. Since that publication, the number of described ostracode genera has more than doubled. It is difficult to survey this worldwide literature and compile all revisions in stratigraphic ranges of older ostracode genera. Therefore, ranges in any synoptic data set, despite ostracodes" large diversity among fossil crustaceans (see below), will be largely minimum ranges.

\section{Malacostracan preservation}

Many malacostracans and other crustaceans have nonmineralized to weakly mineralized exoskeletons. The result is a sporadic fossil record. The most abundant crustaceans in the oceans today, the copepods, have virtually no fossil record, and marine forms are inferred largely from cysts that parasitic copepods produce in echinoderms. Among malacostracans, the fossil record is somewhat better, especially with the Mesozoic evolution of brachyurans with a calcified exoskeleton. Still their known history, like the history of other malacostracan groups, is very sensitive to the geologic distribution of exceptional fossil deposits - Lagerstätten. But if these weakly sclerotized taxa appear more and more frequently in Lagerstätten, then we can infer that they were becoming more important in the biotic environment through time.

\section{Crustacean diversity in the fossil record}

\section{Relative to other arthropods}

Of the approximately 5,800 fossil genera of marine arthropods currently recognized, about 2,600 


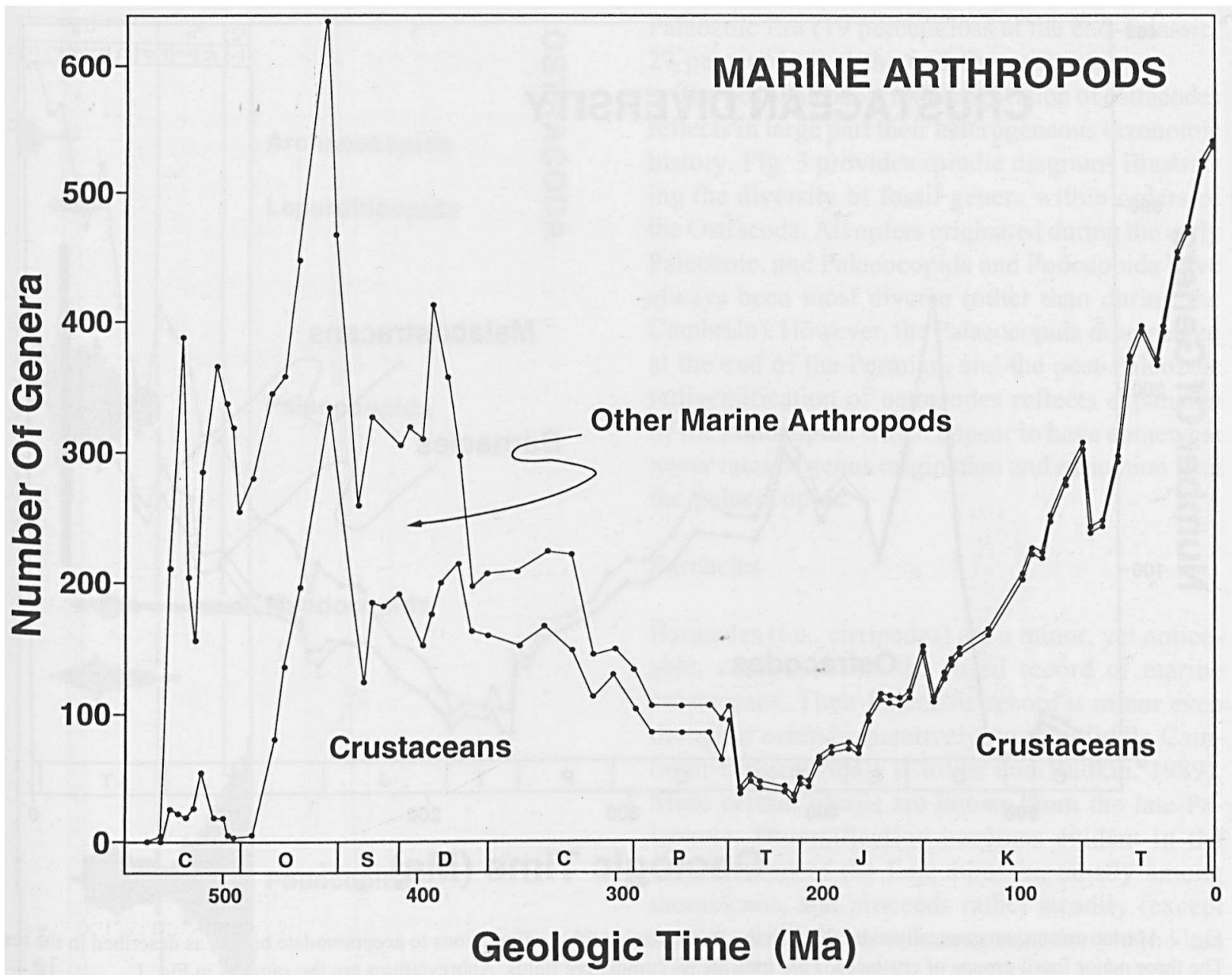

Fig. 1. The described genus diversity of all marine arthropods through the Phanerozoic. Crustacean genus diversity is illustrated by the lower field. Dots indicate data points. "Ma" is millions of years before present. Abbreviations for geologic periods are as follows: $\mathrm{C}=$ Cambrian; $\mathrm{O}=$ Ordovician; $\mathrm{S}=$ Silurian; $\mathrm{D}=$ Devonian; $\mathrm{C}=$ Carboniferous; $\mathrm{P}=$ Permian; $\mathrm{T}=$ Triassic; $\mathrm{J}=\mathrm{Jurassic} ; \mathrm{K}=\mathrm{Cretaceous} ; \mathrm{T}=\mathrm{Tertiary}$.

are crustaceans. The majority of the remaining fossil genera are trilobites, which did not survive the Paleozoic Era. Other groups, such as the extant merostomes and pycnogonids, appear never to have been diverse (except perhaps for the eurypterids). This pattern is illustrated in Fig. 1, which exhibits the total described diversity of marine arthropods through the Phanerozoic with crustacean diversity segregated into a separate field. As evident, crustaceans have been important components of marine biodiversity since the Ordovician Period and compose virtually the entire fossil arthropod fauna through the Mesozoic and Cenozoic Eras when they attain maximum observed diversity. However, crus- tacean diversification has not been homogeneous, as described below.

Diversity of major crustacean groups in the fossil record

Fig. 2 illustrates the Phanerozoic history of the three major groups of fossil crustaceans: ostracodes, barnacles (cirripedes), and malacostracans. Total diversity in this graph differs somewhat from that in Fig. 1 because two adjustments have been made to minimize biases in the fossil data. First, genera confined to single stratigraphic intervals have been 


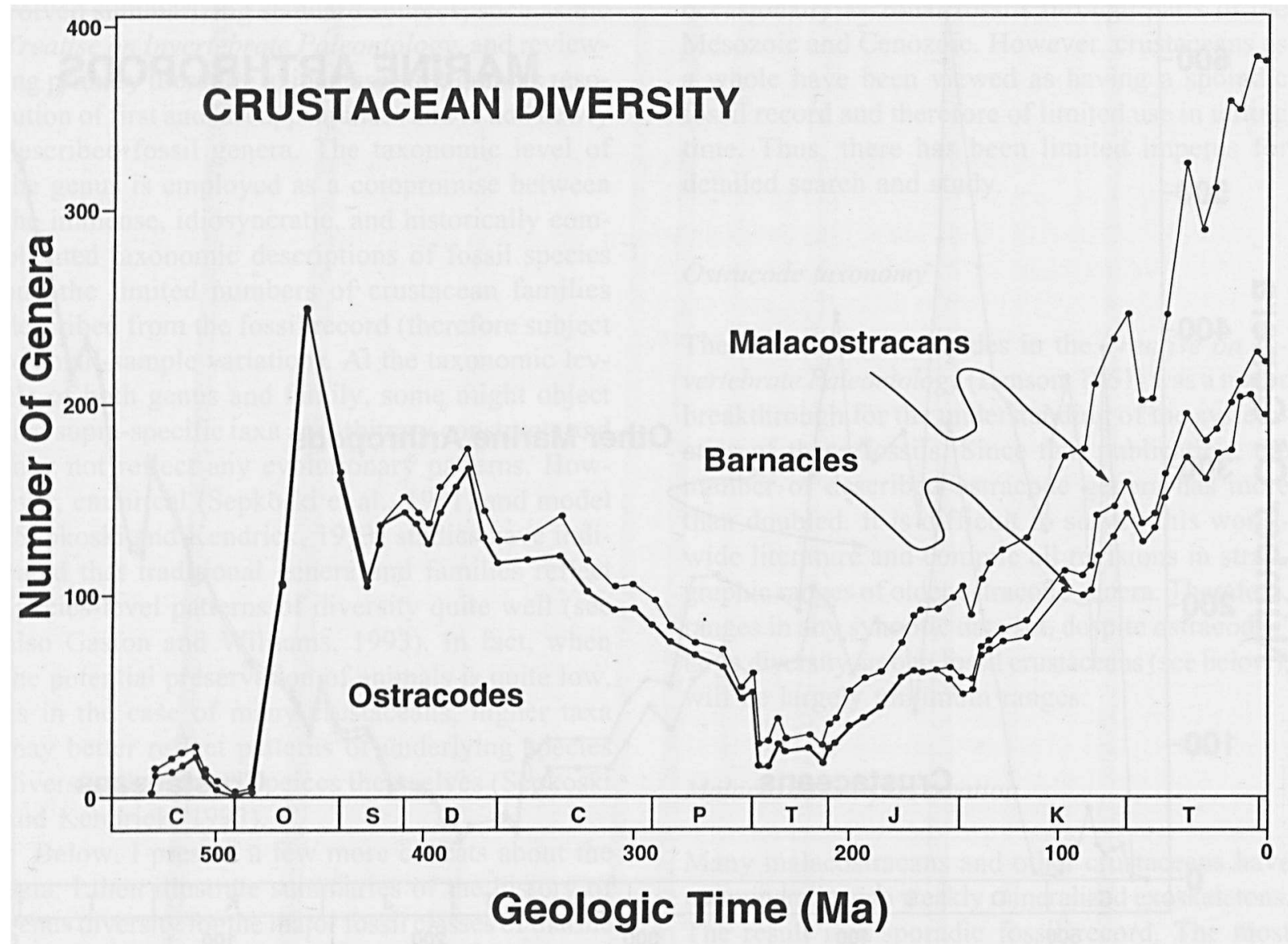

Fig. 2. Marine crustacean genus diversity through the Phanerozoic with manipulations to accommodate biases, as described in the text. The three major fossil groups of crustaceans are indicate by cumulative fields. Abbreviations are the same as in Fig. 1 .

eliminated in order to remove some effects of varying durations of stratigraphic intervals and of extraordinary Lagerstätten (e.g., the Solnhofen Kalken) (see Sepkoski, 1996). Second, extant genera have been counted up until their youngest fossil occurrence (see Sepkoski, 1997) in order to minimize the "pull of the Recent" (Raup, 1979). Thus, while Fig. 1 is purely descriptive, Fig. 2 is somewhat interpretative although still based on counts of genera in the synoptic database.

\section{Ostracodes}

Ostracodes are the major component of the crustacean marine fossil record, constituting nearly 75 percent of accepted genera and dominating observed crustacean diversity throughout the Phanerozoic. I have accepted all Cambrian Archaeocopida (in- cluding bradoriids) as ostracodes, although there is debate about true affinities. Still, their diversity is minor compared to the massive numbers of true ostracodes (e.g., palaeocopids) in the Ordovician. Ostracodes were an important component of the Ordovician radiations and, in fact, attained their maximum fossil diversity during the Caradocian. (However, this may be somewhat artifactual because of intense study of Ordovician ostracodes in Baltic limestones.)

Ostracodes suffered greatly at the end-Ordovician mass extinction (nearly 60 percent decline) and then recovered somewhat during the mid-Paleozoic, like many other members of the Paleozoic evolutionary fauna (see below). Ostracodes experienced decline again at the Late Devonian (Frasnian) mass extinction and appear to have undergone nearly continuous attrition through the 


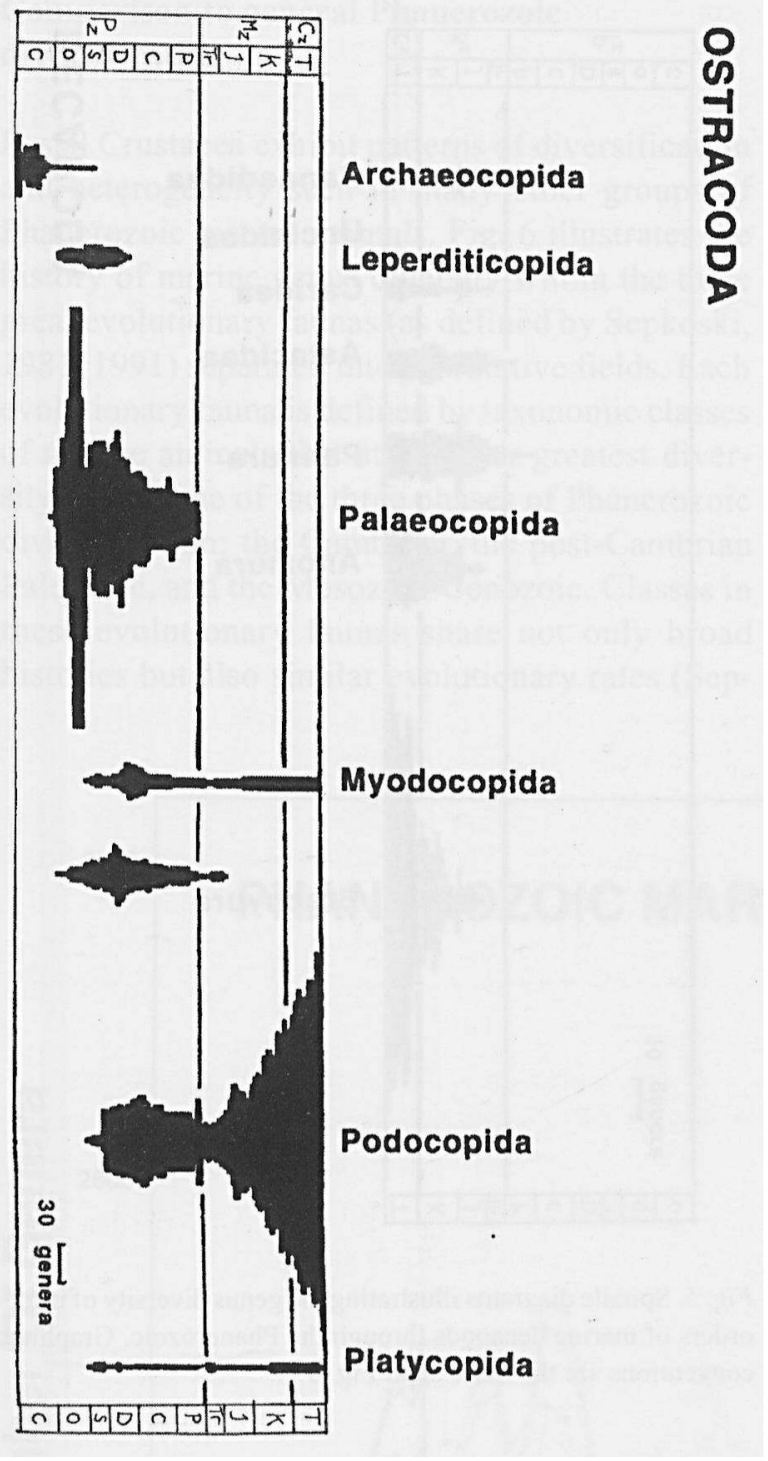

Fig. 3. Spindle diagrams illustrating the genus diversity of marine ostracode orders through the Phanerozoic. The three vertical fields are for the Paleozoic, Mesozoic, and Cenozoic Eras; Phanerozoic periods are indicated in the margins, with abbreviations as in Fig. 1. The spindle diagrams are symmetrical, showing total known fossil diversity. The scale is given in the lower left of the diagram.

late Paleozoic. At the end of the Permian, 80 percent of the remaining ostracode genera became extinct.

The post-Paleozoic history of ostracode diversity is one of recovery, although perhaps not to levels experienced during their Ordovician radiation. The post-Paleozoic genera suffered at some extinction events but not to the same exent as during the
Paleozoic Era (19 percent loss at the end-Triassic, 27 percent loss at the end-Cretaceous).

The post-Paleozoic rediversification of ostracodes reflects in large part their heterogeneous taxonomic history. Fig. 3 provides spindle diagrams illustrating the diversity of fossil genera within orders of the Ostracoda. All orders originated during the early Paleozoic, and Palaeocopida and Podocopida have always been most diverse (other than during the Cambrian). However, the Palaeocopida disappeared at the end of the Permian, and the post-Paleozoic rediversification of ostracodes reflects expansion of the Podocopida which appear to have somewhat lower rates of genus origination and extinction than the palaeocopids.

\section{Barnacles}

Barnacles (i.e., cirripedes) are a minor, yet noticeable, component of the fossil record of marine crustaceans. Their Paleozoic record is minor even though it extends, putatively, to the Middle Cambrian Burgess Shale (Collins and Rudkin, 1989). More certain fossils are known from the late $\mathrm{Pa}$ leozoic. Diversification becomes evident in the fossil record of the Late Jurassic, mostly among thoracicans, and proceeds rather steadily (except for the end-Cretaceous mass extinction) to the late Cenozoic.

\section{Malacostracans}

Malacostracan crustaceans have a history of postPaleozoic diversification like that of barnacles, but they are also taxonomically heterogeneous like ostracodes. Basal malacostracans have some diversity in the Cambrian, as illustrated in Fig. 4 where the several genera are lumped into the "Canadaspida." Most malacostracan diversity in the midPaleozoic is contributed by the "phyllocarids" which persist to the Recent in low diversity. Late Paleozoic Lagerstätten contain a number of disparate groups of malacostracans, including early representatives of the Tanaidacea and Isopoda, which never appear diverse in the fossil record, probably because of rare preservation.

The main component of observed post-Paleozoic diversification of malacostracans is the deca- 


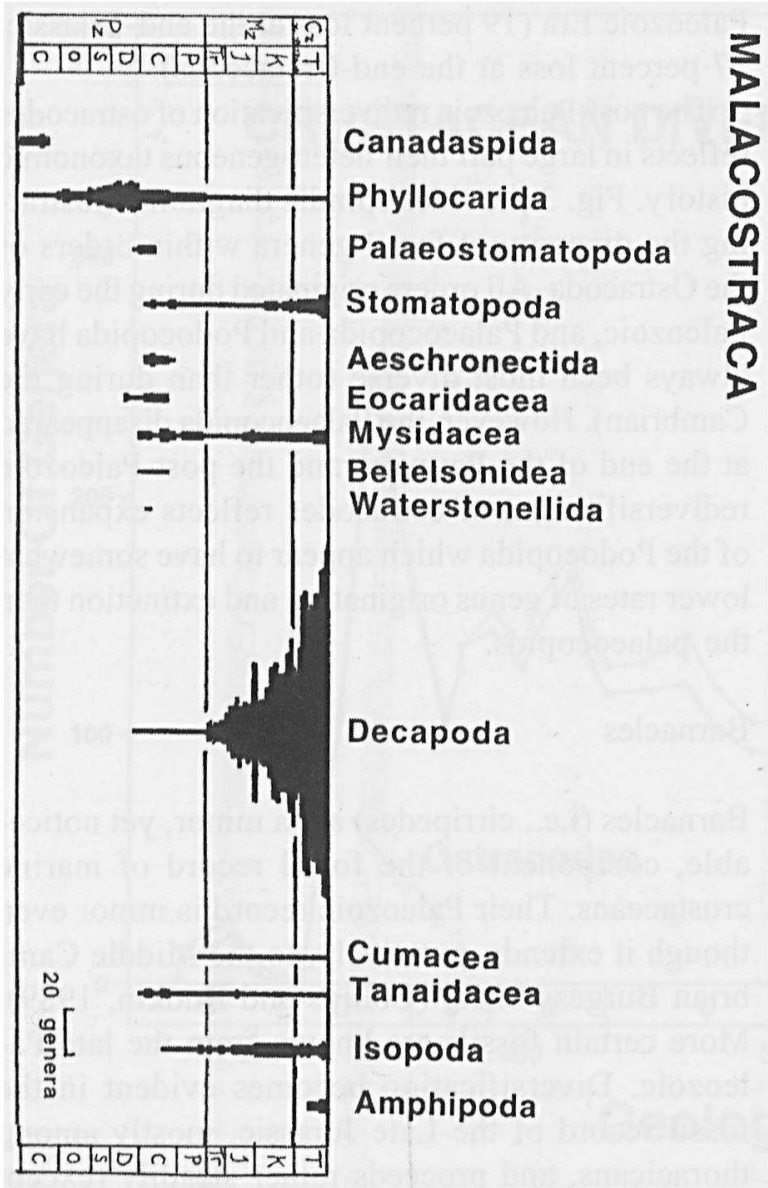

Fig. 4. Spindle diagrams illustrating the genus diversity of marine malacostracan orders through the Phanerozoic. Graphing conventions are the same as in Fig. 3.

pods, as illustrated in Fig. 4. This group is reported first from the latest Devonian (Schram et al., 1978) and has few fossil occurrences during the succeeding Paleozoic. With the post-Permian recovery, fossils and genera become more abundant, especially in Lagerstätten. The Solnhofen, reflected in Fig. 4 by the narrow bar at the top of the Jurassic, contains many more decapod genera than any previous Lagerstätte. After the Solnhofen, genus diversity recorded in the fossil record continues to increase to a late Cenozoic maximum.

The late Mesozoic-Cenozoic expansion of decapod diversity is largely a function of brachyuran radiation, as illustrated in Fig. 5. This is probably a real (if incomplete) pattern since crabs tend to have well-mineralized skeletons; are found increas-

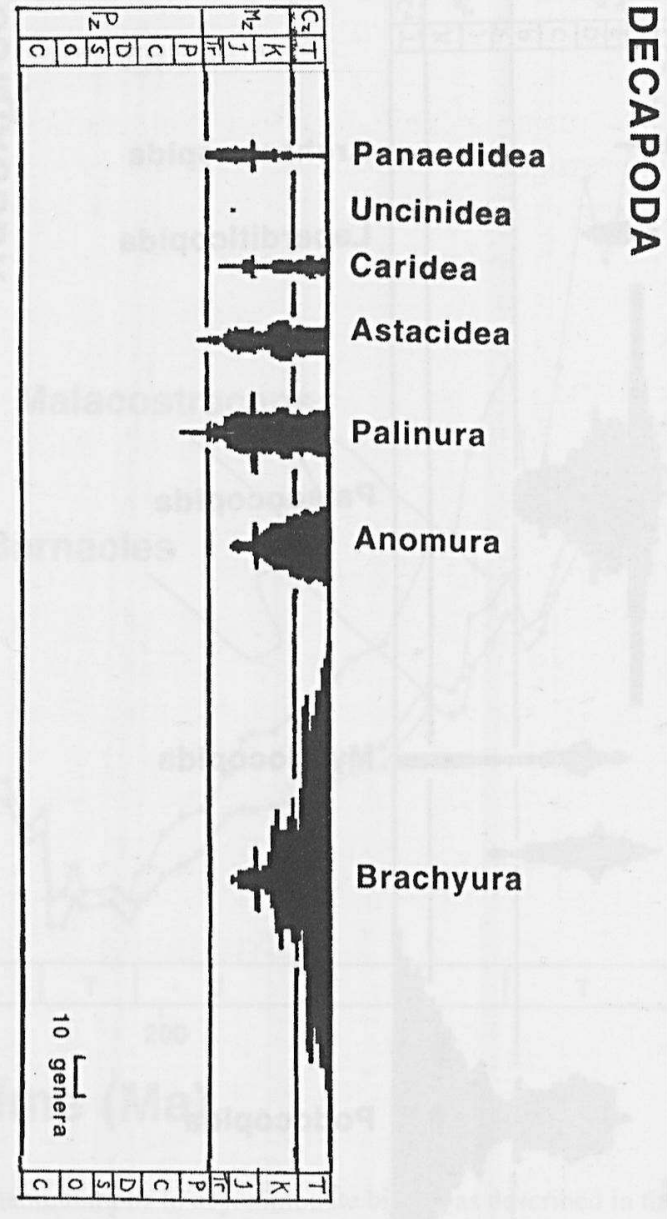

Fig. 5. Spindle diagrams illustrating the genus diversity of infraorders of marine decapods through the Phanerozoic. Graphing conventions are the same as in Fig. 3.

ingly through the Cretaceous and Cenozoic outside of exceptional Lagerstätten; and are implicated in the evolutionary development of defensive morphologies among many molluscan prey through the same time period (Vermeij, 1987). The Astacidea and Palinura ("lobsters") share many of the same features so that their fossil histories of diversity may be similarly reflective of true diversification (despite the spike in the number of genera of palinurans at the Solnhofen). On the other hand, the history of low diversity of the Penaeoidea ("shrimps") almost certainly reflects low preservation of this weakly sclerotized group. 


\section{Comparison to general Phanerozoic diversification}

Fossil Crustacea exhibit patterns of diversification and heterogeneity seen in many other groups of Phanerozoic marine animals. Fig. 6 illustrates the history of marine genus diversity within the three great evolutionary faunas (as defined by Sepkoski, 1981, 1991) separated into cumulative fields. Each evolutionary fauna is defined by taxonomic classes of marine animals that attain their greatest diversity during one of the three phases of Phanerozoic diversification: the Cambrian, the post-Cambrian Paleozoic, and the Mesozoic-Cenozoic. Classes in these evolutionary faunas share not only broad histories but also similar evolutionary rates (Sep- koski, 1984, 1998) and similar habitats, at least during the Paleozoic Era (Sepkoski, 1991).

Malacostracans and barnacles resemble most members of the Modern evolutionary fauna, such as bivalves and gastropods, and especially echinoids and osteichthyan fishes. These are groups present during the Paleozoic Era but with far lower diversity than today. Ostracodes, on the other hand, are better classified within the Paleozoic evolutionary fauna despite their dramatic recovery of diversity (and abundance) during the Mesozoic and Cenozoic Eras. Their history and taxonomic heterogeneity are not unlike those of several other major groups that are classified in the Paleozoic fauna, notably the anthozoan corals and the cephalopods. The stony corals of the Paleozoic Era

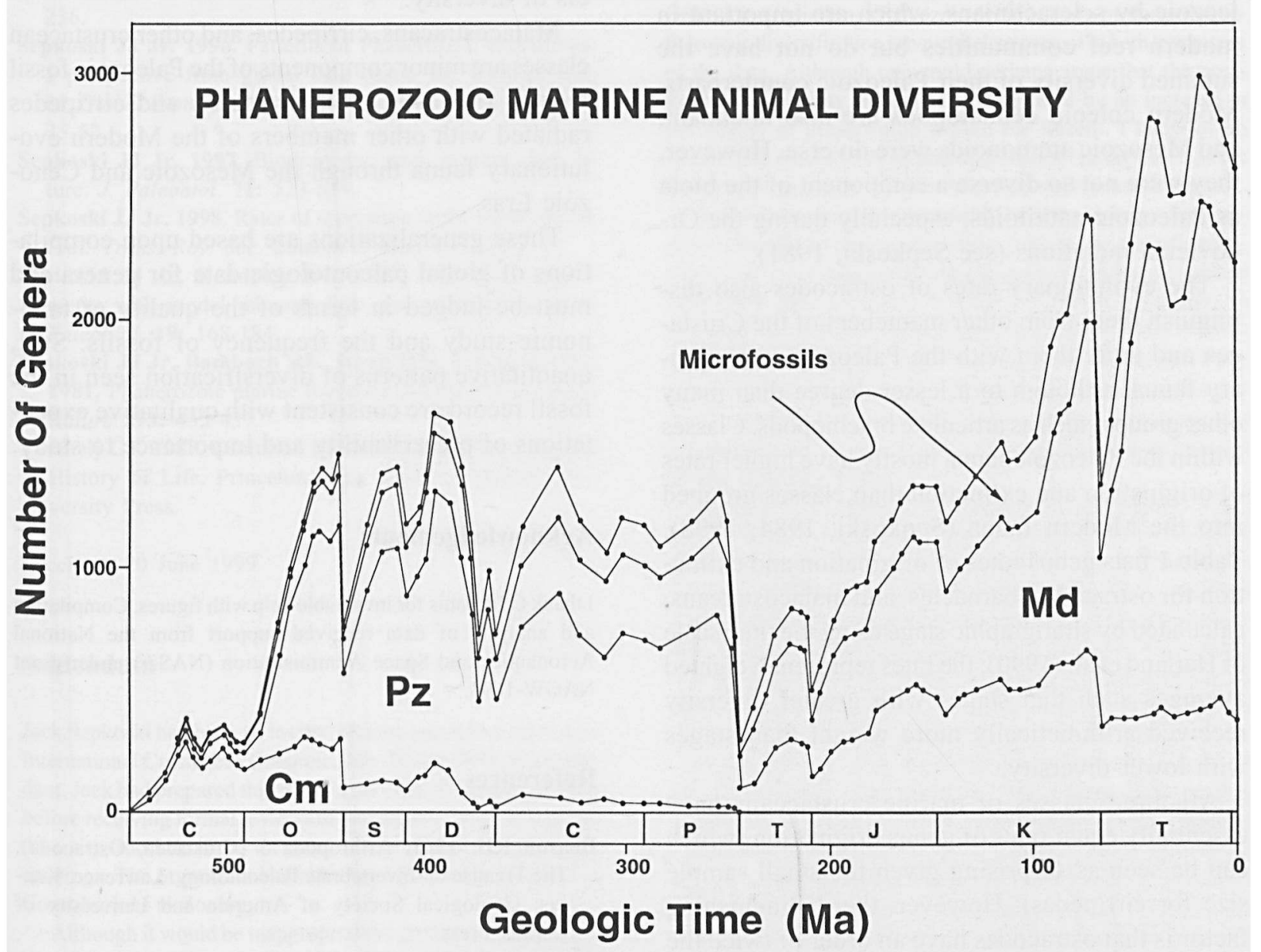

Fig. 6. Genus diversity of the three great evolutionary faunas of the Phanerozoic marine fossil record: "Cm"=Cambrian fauna; "Pz"=Paleozoic fauna; "Md"=Modern fauna. "Microfossils" indicates the diversity of the animal-like Foraminifera and Radiolaria, which can be considered components of the Modern evolutionary fauna. Abbreviations are the same as in Fig. 1. 
Table I. Rates of origination (Orig.) and extinction (Ext.) for genera of Phanerozoic crustaceans that span more than one stratigraphic interval, weighted by diversity (see text). Rates are per-genus rates in units of originations or extinctions per genus per million years. Number of genera indicates actual numbers used in the calculations; total number of genera indicates all numbers in the database. (Several dozen problematical fossil Crustacea that cannot be placed in these three classes are not included in the numbers.)

\begin{tabular}{lcccc}
\hline Class & Orig. & Ext. & $\begin{array}{l}\text { Number } \\
\text { of genera }\end{array}$ & $\begin{array}{l}\text { Total } \\
\text { number }\end{array}$ \\
\hline Ostracoda & 0.025 & 0.021 & 1189 & 1939 \\
Cirripedia & 0.021 & 0.007 & 78 & 93 \\
Malacostraca & 0.024 & 0.012 & 361 & 538 \\
\hline
\end{tabular}

(rugosans and tabulates) became extinct at the end of the Permian and were replaced in the post-Paleozoic by scleractinians, which are important in modern reef communities but do not have the summed diversity of their Paleozoic counterparts. Modern coleoid cephalopods are also abundant, and Mesozoic ammonoids were diverse. However, they were not so diverse a component of the biota as Paleozoic nautiloids, especially during the Ordovician radiations (see Sepkoski, 1981).

The evolutionary rates of ostracodes also distinguish them from other memebers of the Crustacea and unite them with the Paleozoic evolutionary fauna, although to a lesser degree than many other groups, such as articulate brachiopods. Classes within the Paleozoic fauna mostly have higher rates of origination and extinction than classes grouped into the Modern fauna (Sepkoski, 1984, 1998). Table 1 lists genus rates of origination and extipction for ostracodes, barnacles, and malacostracahs, calculated by stratigraphic stage using the time scale of Harland et al. (1990); the rates represent weighted averages such that stages with greater diversity received arithmetically more weight than stages with lower diversity.

All three classes of marine crustaceans have essentially equal rates of genus origination (which can be seen as surprising given the small sample size for cirripedes). However, the distinguishing factor is that ostracodes have an order of twice the rate of extinction of the other two groups. This is characteristic of the high turnover rates of members of the Paleozoic evolutionary fauna in com- parison to the Modern fauna. It is reflected in the greater volatility of ostracodes at mass extinctions, again a characteristic of members of the Paleozoic fauna in general (Sepkoski, 1984).

\section{Summary}

Crustaceans compose the greater part of fossil arthropod diversity from the mid-Paleozoic to the Recent. Their history is heterogeneous, however. Ostracodes were the most important crustacean component of the Ordovician radiations, but their observed diversity waned through the later Paleozoic. After the end-Permian mass extinction, which eliminated palaeocopids, podocopids and other surviving orders radiated to nearly Paleozoic levels of diversity.

Malacostracans, cirripedes, and other crustacean classes are minor components of the Paleozoic fossil record. However, malacostracans and cirripedes radiated with other members of the Modern evolutionary fauna through the Mesozoic and Cenozoic Eras.

These generalizations are based upon compilations of global paleontologic data for genera and must be judged in terms of the quality of taxonomic study and the frequency of fossils. Still, quantitative patterns of diversification seen in the fossil record are consistent with qualitative expectations of preservability and importance to study.

\section{Acknowledgements}

I thank C.M. Janis for invaluable help with figures. Compilation and analysis of data received support from the National Aeronautics and Space Administration (NASA) under grant NAGW-1693.

\section{References}

Benson RH. 1961. Arthropoda 3 (Crustacea, Ostracoda). The Treatise on Invertebrate Paleontology. Lawrence, Kansas: Geological Society of America and University of Kansas Press.

Collins D, Rudkin DM. 1981. Priscansermarinus barnetti, a probable lepadomorph barnacle from the Middle Cambrian Burgess Shale of British Columbia. J. Paleontol. 55: 10061015 . 
Gaston KJ, Williams PH. 1993. Mapping the world's species. The hígher taxon approach. Biodiversity Letters I: 2-8.

Harland WB, Armstrong R, Cox AV, Craig LE, Smith AG, Smith DG. 1990. A. Geologic Time Scale 1989. Cambridge: Cambridge University Press.

Labandeira CC, Sepkoski JJ Jr. 1993. Insect diversity in the fossil record. Science 261: 310-315.

Raup DM. 1979. Biases in the fossil record of species and genera. Bull. Carnegie Mus. Nat. Hist. 13: 85-91.

Schram FR, Feldmann RM, Copeland MJ. 1978. The Late Devonian Palaemonidae and the earliest decapod crustaceans. J. Paleontol. 52: 1375-1388.

Sepkoski JJ Jr. 1981. A factor analytic description of the Phanerozoic marine fossil record. Paleobiol. 7: 36-53.

Sepkoski JJ Jr. 1984. A kinetic model of Phanerozoic taxonomic diversity III. Post-Paleozoic families and mass extinctions. Paleobiol. 10: 246-267.

Sepkoski JJ Jr. 1991. Diversity in the Phanerozoic oceans: a partisan review. In: Dudley EC, ed. The Unity of Evolutionary Biology. Portland, Oregon: Dioscorides, 210236.

Sepkoski JJ Jr. 1996. Patterns of Phanerozoíc extinctions: a perspective from global data bases. In: Walliser $\mathrm{OH}_{\text {, }}$ ed. Global Events and Event Stratigraphy. Berlin: Springer, 35-52.

Sepkoski JJ Jr. 1997. Biodiversity: past, present, and future. J. Paleontol. 71: 533-539.

Sepkoski JJ Jr. 1998. Rates of speciation in the fossil record. Phil. Trans. Roy, Soc. London B 353: 315-326.

Sepkoski JJ Jr, Kendrick DC. 1993. Numerical experiments with model monophyletic and paraphyletic taxa. Paleobiol. 19: 168-184.

Sepkoski JJ Jr, Bambach RK, Raup DM, Valentine JW. 1981. Phanerozoic marine diversity and the fossil record. Nature 293: 435-437.

Vermeij GJ. 1987. Evolution and Escalation: An Ecological History of Life. Princeton, New Jersey: Princeton University Press.

Received: 20 June 1999

\section{Addendum}

Jack Sepkoski had been an invited plenary speaker at the Fourth International Crustacean Congress, July 20-24, 1998, in Amsterdam. Jack had prepared this paper from his talk but passed away before receiving formal reviews of his manuscript on crustacean diversity, too late to be included in the formal congress proceedings. The organizers have arranged the publication here in Contributions to Zoology *

Although it would be inappropriate to modify the paper itself or to speculate as to how Jack would have responded, I would like to address some of the points raised by reviewers. .

The two principal criticisms can be paraphrased as follows: (1) The data are of uncertain quality. Some assignments of ge- nera to hìgher taxa are outdated and probably inaccurate. This is especially true of Cambrian forms. Moreover, exceptional deposits such as the Solnhofen are highly biased. (2) Statistical generalizations, such as the one that the ostracodes in general, despite their post-Paleozoic diversification, show evolutionary rates similar to components of the Paleozoic evolutionary fauna, are so abstract as to be of little use in understanding the evolutionary history of Crustacea.

Jack Sepkoski was quite aware of the problems posed by preservational and monographic biases, such as the spikes in diversity that result from exceptionally well-preserved and wellstudied faunas, and the exaggeration of Cenozoic diversity that results from the extension of stratigraphic ranges to the Recent (see Fig. 1). It is largely for this reason that he began several years ago to construct diversity curves, such as those in Fig. 2, with single-interval genera omitted and with extant taxa treated as if they were known from their fossil occurrences only.

There are interesting differences between the Crustacean fields of Fig. 1 and Fig. 2, for example the diversity peaks in the Cambrian (Burgess Shale and other faunas) and Late Jurassic (Solnhofen Limestone) in Fig. 1. The larger-scale pattern of an Ordovician radiation, a Paleozoíc decline, and a prolonged postPaleozoic diversification is nevertheless present in both treatments of the data. Although one could perhaps argue that the postPaleozoic diversity increase is exaggerated by an increase in the quality of preservation toward the Recent, I know of no compelling reason to think that other major features such as the Ordovician radiation and the Paleozoic decline are artifacts.

Jack was continually scrutinizing his data, refining stratigraphic calls, and weighing alternative schemes of classification. Clearly, he never regarded his data as complete, and he recognized their shortcomings, many of which he explicitly discusses in the paper. I would nevertheless argue that the uncertain classification of Cambrian genera, while an important problem for those whose main interest lies in arthropod phylogeny, is a rather minor one in the context of Jack's principal analyses and conclusions, for the trends and events on which he focuses are largely post-Cambrian.

As far as the question of whether statistical analysis of the fossil record is an endeavor worth pursuing, this is certainly not the place to debate the issue. Subjectively, I would argue that the recognition of distinct associations of taxa that have "covarying diversity patterns and similar rates of taxonomic turnover, along with the fact that these associations show some degree of ecological coherence insofar as they tend to be more abundant in certain environments early in their history and to shift or expand their environmental ranges later, is one of the most significant empirical results that paleontology has produced in the past few decades. The specific case of ostracodes mentioned above also provides an interesting example of how apparent exceptions test the rule. The three evolutionary faunas, whose diversity maxima succeed each other, show successively lower rates of taxonomic turnover, and their constituent classes tend to do so as well. In a sense, ostracodes, as statistical members of the Paleozoic fauna, "shouldn't" have diversified so strikingly after the Paleozoic. However, as Jack points out, the order of ostracodes that participates in this post-Paleozoic radiation, the Podocopida, is similar to the Modern evolutionary fauna in having 
relatively low rates of genus turnover. The Ostracoda therefore represent something of an evolutionary microcosm, displaying at a finer scale a pattern similar to that seen in the more broadly defined evolutionary faunas.

A recent study (Adrain JM, Westrop SR. 2000. An empirical assessment of taxic paleobiology. Science 289 * 110-112) compares Sepkoski's trilobite data with data that have been compiled and vetted by trilobite specialists. By showing similar patterns in the two data sets, this study supports the argument that, despite their shortcomings, Sepkoski's data accurately document many aspects of diversity, origination, and extinction in the fossil record.

\section{Míchael Foote}

Dept. of Geophysical Sciences, University of Chicago 